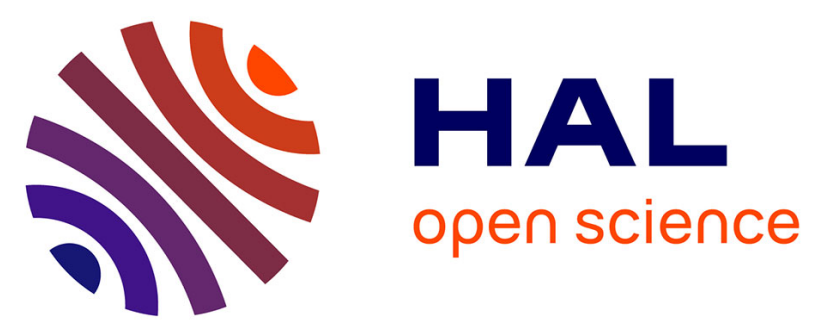

\title{
Cut-off low monitoring by the French VHF-ST-radar network during the ESTIME campaign
}

Jean-Luc Caccia, François Bertin, Bernard Campistron, Vladislav Klaus, Yves Pointin, Joël van Baelen, Richard Wilson

\section{- To cite this version:}

Jean-Luc Caccia, François Bertin, Bernard Campistron, Vladislav Klaus, Yves Pointin, et al.. Cutoff low monitoring by the French VHF-ST-radar network during the ESTIME campaign. Journal of Atmospheric and Solar-Terrestrial Physics, 2000, 62 (8), pp.639-651. 10.1016/S1364-6826(00)000456. hal-01897365

\section{HAL Id: hal-01897365 \\ https://hal.uca.fr/hal-01897365}

Submitted on 12 Aug 2021

HAL is a multi-disciplinary open access archive for the deposit and dissemination of scientific research documents, whether they are published or not. The documents may come from teaching and research institutions in France or abroad, or from public or private research centers.
L'archive ouverte pluridisciplinaire HAL, est destinée au dépôt et à la diffusion de documents scientifiques de niveau recherche, publiés ou non, émanant des établissements d'enseignement et de recherche français ou étrangers, des laboratoires publics ou privés.

\section{(1) (1) $\$$}

Distributed under a Creative Commons Attribution - NonCommercial - NoDerivatives| 4.0 


\title{
Cut-off low monitoring by the French VHF-ST-radar network during the ESTIME campaign
}

\author{
J.-L. Caccia ${ }^{\mathrm{a}, *}$, F. Bertin $^{\mathrm{b}}$, B. Campistron ${ }^{\mathrm{c}}$, V. Klaus ${ }^{\mathrm{d}}$, Y. Pointin ${ }^{\mathrm{e}}$, J. van \\ Baelen $^{\mathrm{d}}$, R. Wilson ${ }^{\mathrm{f}}$ \\ ${ }^{a}$ Laboratoire de Sondages Electromagnétiques de l'Environnement Terrestre/CNRS, Université de Toulon et du Var, 83957 La Garde, \\ France \\ ${ }^{\mathrm{b}}$ Centre d'étude de l'Environnement Terrestre et Planétaire/CNRS, 94107 St-Maur, France \\ ${ }^{\mathrm{c}}$ Laboratoire d'Aérologie/CNRS, Observatoire Midi-Pyrénées, 65300 Campistrous, France \\ ${ }^{\mathrm{d}}$ Centre National de Recherches Météorologiques/CNRS, Météo-France, 31057 Toulouse, France \\ e Laboratoire de Météorologie Physique, Observatoire de Physique du Globe de Clermont/CNRS, Université Blaise Pascal, 63177 \\ Aubière, France \\ ${ }^{\mathrm{f}}$ Service d'Aéronomie du CNRS, Université de Paris VI, Jussieu, 75252 Paris, France
}

In order to investigate mesoscale strato-tropospheric exchanges, the field campaign 'Echanges StratosphèreTroposphère: Investigations à Moyenne Echelle' was conducted in France from late 1993 to mid 1995 and focused on cut-off low events. It involved the French research network of five VHF (Very High Frequency) ST (StratoTropospheric) radars deployed in southern France. Observations corresponding to three Intensive Observing Periods are reported here. The radar data analyzed and discussed are time-height diagrams of the aspect ratio (AR), that is, the vertical to oblique beam-returned power ratio, used for monitoring three cut-off low events. In order to discuss the validity of the method, $506 \mathrm{~h}$ of radar AR data were compared with time-height diagrams of the static stability and the humidity obtained from synoptic European Center for Medium-range Weather Forecasts model analyses. A dataset corresponding to $297 \mathrm{~h}$ of observations is analyzed and discussed here. It is concluded that the AR is a good tracer to document cut-off low events, including tropopause folding identification and the detection of tropospheric air masses of enhanced stability, in dry or weakly humid cases. On the other hand, although the effects of the specific humidity and its gradients on VHF radar echo power could not be extensively investigated, our results suggest that the same parameter cannot be used at mid- and lower-tropospheric levels when the effects of specific humidity significantly reinforce the moist static stability. It is important to take into account these insights in the context of future observing campaigns in which a network of VHF-ST-radars will be involved, and where their role will be to observe and to document the evolution of upper-level features or potential vorticity streamers, or more generally stratospheric-tropospheric exchanges.

Keywords: VHF-ST-radar; Aspect ratio; Moist static stability; Cut-off lows; Stratosphere-troposphere exchanges

\footnotetext{
* Corresponding author.

E-mail address: caccia@1seet.univ-tln.fr (J.L. Caccia).
} 


\section{Introduction}

ESTIME stands for 'Echanges Stratosphère-Troposphère: Investigations á Moyenne Echelle'. It is a campaign devoted to the characterization of the atmospheric exchange that takes place across tropopause folds and cut-off lows at regional scale. ESTIME is a collaboration between the French ST radar research network group, the French ozone monitoring group, and the modeling group of the Dutch weather service (KNMI). The general objective was to collect data of dynamical parameters and of a stratospheric tracer (ozone) to study the development of cut-off lows over Europe. Preliminary results were already reported (van Baelen et al., 1994; Bertin et al., 1996), and first results concerning specific case studies of cut-off low have already been obtained (Campistron et al., 1999; Ravetta et al., 1999).

Although the physics of cut-off low developments and related phenomena is not the concern of this paper, results from earlier works can be summarized as follows. The identification of mechanisms driving the upper potential vorticity (PV) field evolution and the related tracer transport to the troposphere has been addressed by several authors through the modeling of case studies (Ebel et al., 1991; Lamarque and Hess, 1994; Wirth, 1995) and through meteorological analysis, radiosonde data and satellite data (total ozone and cloud images) (Price and Vaughan, 1993; Ancellet et al., 1994). Cut-off lows are regions of vigorous mixing and diabatic heating, especially in summer. According to Lamarque and Hess (1994), penetration of cumulonimbus anvils in the lower stratosphere, followed by radiative destabilization is a very significant mechanism for exchanging air between the troposphere and the stratosphere. The possible mixing at the tropopause level in a cut-off cyclone has been stressed in the observational work of Shapiro (1980) and Danielsen et al. (1987), but is also expected at the bottom of a deep trough with high vorticity according to the theoretical analysis of Hoskins and Bretherton (1972).

Here, we are interested in the interpretation of data from five VHF (Very High Frequency) ST (StratoTropospheric) radars which were collected during three cut-off low events: the IOPs (Intensive Observing Periods) 1, 2 and 3 of the ESTIME campaign. The parameter discussed is the aspect ratio (AR), that is, the vertical to oblique echo power ratio. The reason for this choice is that this parameter has already been shown to be appropriate for monitoring an upper-level front passage above a VHF-ST-radar (Caccia and Cammas, 1998, hereafter noted CC98). In case of cutoff low, air masses of polar origin, characterized by a low tropopause altitude, move to mid-latitude regions and lower the transition level of enhanced stability. Furthermore, tropopause foldings can bring down, within the troposphere, layers of stratospheric air. Therefore, as for the upper-level fronts, we expect the AR method to be capable of detecting such air masses of unusual high stability. Details concerning the AR calculation and its interpretation are given in CC98 and are summarized in the next section.

Observations of frontal or cut-off low passages using VHF-ST-radars have already been reported in several papers (e.g. Röttger, 1979; Larsen and Röttger, 1985; Neiman and Shapiro, 1989; Fukao et al., 1989; Crochet et al., 1990; May et al., 1991; Neiman et al., 1992). In these experimental studies, the wind and/or the vertical echo power, or vertical reflectivity, fields were used to describe the mesoscale time-height structure of the frontal zone above the radar site. The radar vertical reflectivity depends both on the atmospheric moist static stability, via the specular reflection, and on the isotropic turbulence, via the turbulent backscattering (Gage and Balsley, 1980; Röttger, 1980). Following Gage et al. (1981), the reflection echo power is proportional to $M^{2}, M$ being the generalized refractive index gradient, given by Ottersten (1969), which becomes directly proportional to $N^{4}, N$ being the Brunt-Väisälä (BV) pulsation, in a dry atmosphere. The turbulence echo is proportional to the $C_{N}^{2}$ (e.g. Luce et al., 1996), that is, the refractive index structure constant, which is itself proportional to $N^{2}$ (provided that $N^{2}$ can be defined, i.e. the atmosphere is stable), but also to small scale perturbations due to turbulent and/or laminar flows. Therefore, the time-height atmospheric regions of high static stability could be unambiguously detected from radar vertical reflectivity enhancements, provided that the isotropic turbulence is not preponderant, which is generally the case at high tropospheric and stratospheric levels. Using this method, Röttger (1979), Larsen and Röttger (1985) and May et al. (1991) have been able to detect stable air masses exchanged between the stratosphere and the troposphere, and the associated tropopause breaks or folds. On the other hand, in these works, stable air layers were impossible to detect in the mid and low troposphere because of the presence of very strong turbulence that resulted in both significant temperature and humidity fluctuations. It was the purpose of CC98 to propose the AR method for taking into account the isotropic turbulence contribution to the radar vertical reflectivity using the simultaneous knowledge of the echo power obtained from two oblique radar beams slanted at $15^{\circ}$, which is known to be only dependent on the isotropic turbulence (Hocking et al., 1990; Luce et al., 1996), and by assuming that the $C_{N}^{2}$ is invariant, at a given altitude, from one beam to another. In this method, if one assumes that the atmosphere is dry or weakly humid, $\mathrm{AR}$ is interpreted as an atmospheric static stability signature. The advantage of the AR method is to allow a 
more complete description of the atmospheric mesoscale features above the radar site, especially when the associated stable air goes down into the low troposphere.

In the present paper, our purpose is to apply the same method on data obtained from five VHF-STradars to study the mesoscale aspects of three cut-off low events and then to investigate a possible extension of the domain over which the method is valid. Furthermore, it is the first time that experimental results concerning all the three IOPs of ESTIME are presented. Some aspects of the synoptic model analyses, used in this paper, are briefly described in the following section. Then, the radar measurements and the methodology are presented. In the following section, the experimental results and radar data/model analyses comparisons are reported along with a brief description of the meteorological situation. Finally, before a section of concluding remarks, a section is devoted to a discussion about the reliability of the AR method for monitoring any stratosphere-troposphere exchange process in dry and humid situations.

\section{Brief description of ECMWF analyses}

During the ESTIME campaign, the European Center of Medium-range Weather Forecasts (ECMWF) produced routine global analyses for the four main synoptic hours, 00, 06, 12 and 18UTC using a numerical model based on a T213/L31 (triangular truncation, resolving up to wave number 213 in spectral space, linearly reduced Gaussian grid with 31 levels from the Earth's surface to $10 \mathrm{hPa}$ ). The grid spacing was then close to $100 \mathrm{~km}$. The integration scheme was a semi-Lagrangian, two-timelevel semi-implicit formulation with a $20 \mathrm{~min}$ time step. The variables at each grid point included the wind, the temperature, the humidity, the cloud fraction and the water/ice content (also the pressure at surface grid-points). Several physical processes are parametrized on the Gaussian grid including orography, stratiform and convective precipitation, ground and sea roughness, and so on.

Every $6 \mathrm{~h}$, a correction process to the predicted fields was based upon the data assimilation and analysis of the global wind, the temperature, the surface pressure and the humidity errors between the measured values and the corresponding predicted values. The fields analyzed in this paper are the filtered results of this correction process.

\section{VHF-ST-radar measurements and AR method}

\subsection{Experimental conditions of the VHF-ST-radar network}

Our network consists of five VHF-ST-radars of the same so-called Platteville radar type already described by Gage and Balsley (1978) and Larsen and Röttger (1982). Their measurements lead to the time evolution of the vertical profiles of the three wind components and of the atmospheric reflectivity observed in three directions. In brief, the wind velocity is estimated from the frequency corresponding to the mean Doppler shift obtained in the radar echo, whereas the reflectivity is estimated from the signal-to-noise ratio (SNR) in the corresponding Doppler spectrum. Table 1 presents the radar locations (also see Fig. 1) and the institutes responsible for the radar operation.

All the radars work with a frequency of $45 \mathrm{MHz}$ and an average power of $800 \mathrm{~W}$, except for the OHP radar of $72.5 \mathrm{MHz}$ frequency and $720 \mathrm{~W}$ mean power. Each radar was sequentially switched among three different antennas of which one was pointed vertically upward and the other two were slanted at $15^{\circ}$ to the vertical and had perpendicular azimuthal orientations. A radar pulse and gates of $2.5 \mu$ s length allowed each radar to investigate the atmosphere from $2-4 \mathrm{~km}$ up to $10-12 \mathrm{~km}$ with a vertical resolution and sampling step of $375 \mathrm{~m}$. The tangential resolution is given by the radar beamwidth, here $5.5^{\circ}$ at $-3 \mathrm{~dB}$, and ranged from $190-380 \mathrm{~m}$ to $960-1150 \mathrm{~m}$. The vertical profiles of wind and reflectivity were obtained every $5 \mathrm{~min}$, but here, half-hourly averaged data are used and presented, which is compatible with the sampling of a mesoscale process.

\subsection{Summary of the AR method}

All the details concerning the AR calculation and method have been presented in CC98. We will simply summarize them here.

For each radar gate, thus each time and altitude, $\mathrm{AR}$ is calculated as the vertical to oblique echo power ratio. The oblique echo power used in this calculation is the average between the echo powers obtained from both oblique beams, then vertically interpolated such that the altitudes are the same for all three beams. In the following, AR values are presented in time-height cross-sections, the height being taken along the vertical axis above the radar locations.

On one hand, as already mentioned, we assume the vertical echo power to be caused by both isotropic turbulence backscattering and specular reflection due to the potential refractivity gradient, thus due the to the moist atmospheric stability, that is, the square value of the BV pulsation (Gage and Balsley, 1980; Röttger, 
1980). On the other hand, we assume the oblique echo power to be only due to isotropic turbulence, via the $C_{N}^{2}$, since the off-zenith angle used in our radar configuration is $15^{\circ}$, thus greater than the minimum value of $10^{\circ}$ required for this assumption to be accepted (Hocking et al., 1990; Luce et al., 1996; Tsuda et al., 1997). Following these two assumptions, AR quantifies stability against turbulence. In CC98, an AR > 3-criterion was used as the detection threshold of a significantly stable air mass. This value was justified after the histogram of the values of the oblique-to-oblique echo power ratio had been computed and showed that more than $90 \%$ of those values were found in the range of $1 / 3$ to 3 at mid- and low-tropospheric levels. Since the calculation was made from oblique-beam measurements, the value of 3 can thus be seen as the largest $\mathrm{AR}$ values obtainable in the case of isotropic turbulence scattering. Hence, higher values indicate the presence of stable air masses. The location of the histogram maximum also reveals if a bias exists between the two orthogonal oblique measurements. In absence of any bias, the histogram peak is centered on 1 , or $0 \mathrm{~dB}$. This bias must be corrected in the AR calculation so that the mean echo power obtained by both oblique beams is the same for any given observation period. Such a bias can be attributed to the different losses in the different wires and components of the antenna sub-networks corresponding to the different radar beams and to differences in the cosmic noise level observed in different directions.

\subsection{Application to the radar data of the ESTIME campaign}

We used the concept of IOP, corresponding to the activation of the network when a relevant cut-off low was forecasted over the network area by the operational models (ARPEGE and ECMWF). The three IOP's took place as follows: IOP1 between 23 October 1993, 00UTC, and 24 October 1993, 23UTC; IOP2 between 25 June 1994, 21UTC, and 27 June 1994,
14UTC; IOP3 between 4 March 1995, 00UTC, and 5 March 1995, 09UTC. The PV-horizontal fields at 300 hPa (about $9 \mathrm{~km}$ ASL) obtained from ECMWF model analyses and corresponding to these three situations are shown in Fig. 1(a)-(c), respectively. The hatched parts indicate the region, where PV $>2$, which, following the dynamic tropopause definition of Hoskins et al. (1985), that is PV $=2$, also show the area where the tropopause falls below about $9 \mathrm{~km}$. Roughly speaking, this kind of display gives an indication of the cut-off low boundaries above the western Europe. The radar installation sites are also indicated in Fig. 1. The distances between the radar stations range from 70 (Toulouse-Lannemezan and OHP-Toulon) to 450 $\mathrm{km}$ (Lannemezan-Toulon).

Fig. 1(c) shows that, during IOP3, the upper-level PV anomaly was actually not a cut-off low, since the area of high PV values (see the hatched area) above the radar network is not fully isolated from the high latitude PV field and the wind fields at $900 \mathrm{hPa}$ (not shown here) does not exhibit fully circular trajectories. Nevertheless, the associated trough was very narrow and a tropopause folding was developped along the west side of the PV anomaly. The fold is eastwards advected during the day over the ST radar network (see Figs. 7 and 8 presented in the following section). Therefore, the IOP3 corresponds to a situation which is not far from being a cut-off low. Although this discussion would be important in the context of meteorological studies, it is not of high importance here according to the purpose of the present paper.

For each radar and for each IOP, where data are available, the histogram of the values of the obliqueto-oblique power ratio were computed. For all the cases, $81-97 \%$ of the values were found between $1 / 3$ and 3 , that is, between -5 and $5 \mathrm{~dB}$, around the histogram peak. The AR > 3-criterion for stable air mass detection can thus be applied. Furthermore, the peak center positions, or the biases, were found between 0 and $2 \mathrm{~dB}$ (in absolute value). They were systematically taken into account in the AR calculation.

Table 1

Description of the ESTIME VHF-ST-radar network. The institute names (with radar frequency), the location names and the geographical coordinates (latitude and longitude) corresponding to the five VHF-ST-radars are indicated

\begin{tabular}{lll}
\hline Institute name & Location name & Coordinates \\
\hline LaMP/OPGC (45 MHz) & Clermont-Ferrand & $45^{\circ} 45^{\prime} \mathrm{N}, 03^{\circ} 6^{\prime} \mathrm{E}$ \\
CRA/LA/OMP (45 MHz) & Lannemezan & $43^{\circ} 08^{\prime} \mathrm{N}, 00^{\circ} 22^{\prime} \mathrm{E}$ \\
SA/CNRS (72.5 MHz) & Obs. de Haute-Provence & $43^{\circ} 54^{\prime} \mathrm{N}, 05^{\circ} 48^{\prime} \mathrm{E}$ \\
LSEET (45 MHz) & Toulon & $43^{\circ} 10^{\prime} \mathrm{N}, 05^{\circ} 55^{\prime} \mathrm{E}$ \\
CNRM/[Météo-France] (45 MHz) & Toulouse & $43^{\circ} 37^{\prime} \mathrm{N}, 01^{\circ} 26^{\prime} \mathrm{E}$ \\
\hline
\end{tabular}



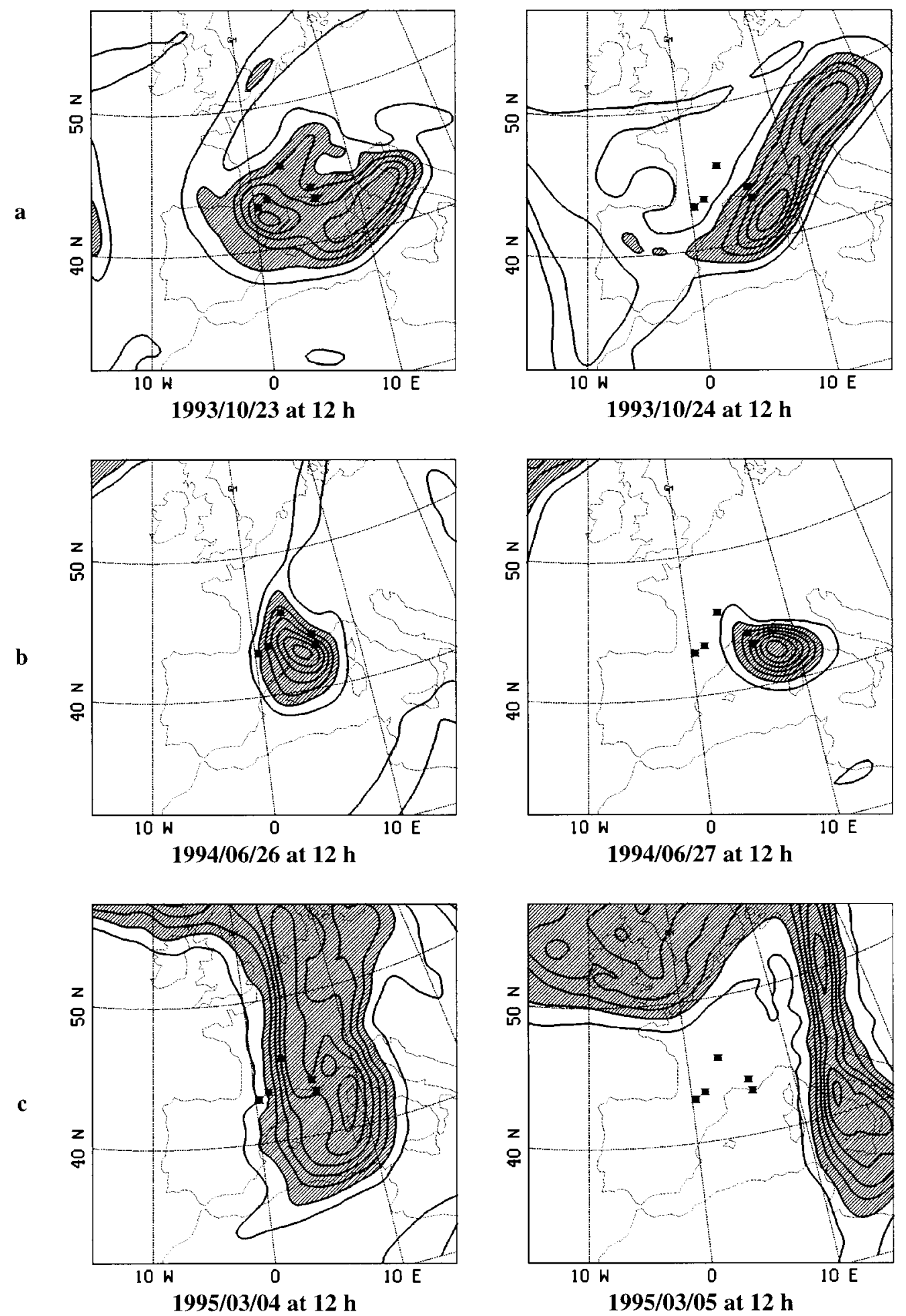

Fig. 1. PV horizontal fields at $300 \mathrm{hPa}$ (about $9 \mathrm{~km} \mathrm{ASL}$ ) above Western Europe for (a) the IOP1, (b) the IOP2 and (c) the IOP3 of ESTIME. A contour is indicated every $1 \mathrm{PV}$ unit. The hatched patterns indicate the areas where PV $>2$, that is, where the dynamic tropopause is below about $9 \mathrm{~km}$. The five radar sites are denoted by stars. 


\section{Experimental results}

\subsection{Radar AR data and model analyses}

A dataset corresponding to a total observation period of $506 \mathrm{~h}$ was collected by the five VHF-STradars during the three cut-off low events of the ESTIME campaign. As illustrations and to support the discussion (see the following section) seven figures are presented here, corresponding to a total observation period of $297 \mathrm{~h}$. All these figures (Figs. 2-8) consist of systematic comparisons, in the time-height cross-sections, between (a) AR and (b) moist static stability. A contour value of 3 is used in the AR representation, so that the black areas indicate time-height atmospheric regions where the radars are assumed to detect stable air masses. Although the IOPs durations and the radar altitude ranges are not all the same, we have chosen to present all the results with the same altitude and time scales: $13 \mathrm{~km}$, for the $Y$-axis, and $48 \mathrm{~h}$ for the $X$-axis. The moist static stability is derived from ECMWF- model analyses as the square value of the BV pulsation, that is, $N^{2}=\frac{g}{\theta_{\mathrm{e}}} \frac{\partial \theta e}{\partial z}$, where $\theta_{\mathrm{e}}$ is the equivalent potential temperature and $z$ is the altitude. The contour values used in the $\mathrm{BV}$ pulsation cross-sections, $1 \times$ $10^{-4}$ and $3 \times 10^{-4} \mathrm{~s}^{-2}$, correspond to BV periods of 10 and $6 \mathrm{~min}$, respectively. The reason for this choice is that $\mathrm{BV}$ periods greater than $10 \mathrm{~min}$ and smaller than $6 \mathrm{~min}$ are typical characteristics of tropospheric and stratospheric air, respectively. The dynamic tropopause position, calculated with the $\mathrm{PV}=2$ criterion, is also indicated on all the figures. In order to make the discussion of the results easier, contours of the specific humidity values obtained from the ECMWF-model analyses are shown in Figs. 2(b)-8(b). Contour values of 2 (dotted lines) and $3 \mathrm{~g} / \mathrm{kg}$ (dashed lines) were chosen as indicators of the tropospheric levels, where the humidity remains significant. A single contour value of $-0.5 \mathrm{~g} / \mathrm{kg} / \mathrm{km}$ (solid lines) for the model-derived specific humidity gradient is also superimposed so that the absolute value of the gradient is higher and lower

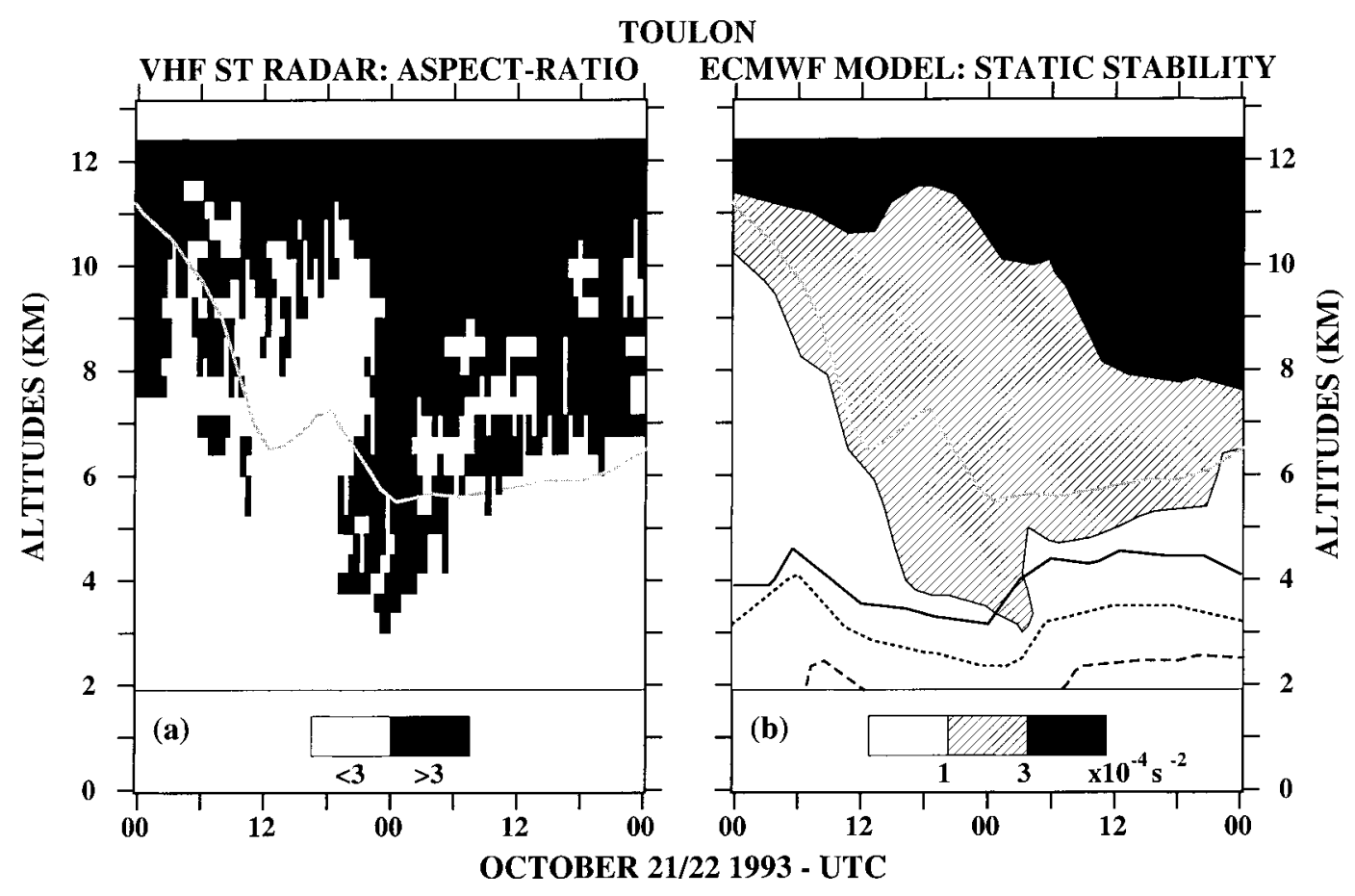

Fig. 2. Time-height cross-sections of (a) the VHF radar aspect ratio (AR) and (b) the ECMWF model moist static stability between 21 October 1993 00UTC and 23 October 1993 00UTC above Toulon. In (a) the white and black patterns correspond to $\mathrm{AR}<3$ and $\mathrm{AR}>3$, respectively. In (b) the white, hatched and black patterns correspond to a BV squared pulsation smaller than $1 \times 10^{-4} \mathrm{~s}^{-2}$, between $1 \times 10^{-4} \mathrm{~s}^{-2}, 3 \times 10^{-4} \mathrm{~s}^{-2}$, and greater than $3 \times 10^{-4} \mathrm{~s}^{-2}$, respectively. Still in (b), two contours of the specific humidity obtained by ECMWF model analyses are shown using level values of $2 \mathrm{~g} / \mathrm{kg}$, dotted line, and $3 \mathrm{~g} / \mathrm{kg}$, dashed line, whereas the solid-line contour indicates the specific humidity gradient using a single level value of $-0.5 \mathrm{~g} / \mathrm{kg} / \mathrm{km}$. The areas below and above this solid line correspond to gradients smaller (thus greater in absolute value) and greater (thus smaller in absolute value) than $-0.5 \mathrm{~g} / \mathrm{kg} / \mathrm{km}$, respectively. In both (a) and (b) the gray curve indicates the time evolution of the dynamical tropopause altitude $(\mathrm{PV}=2)$. 


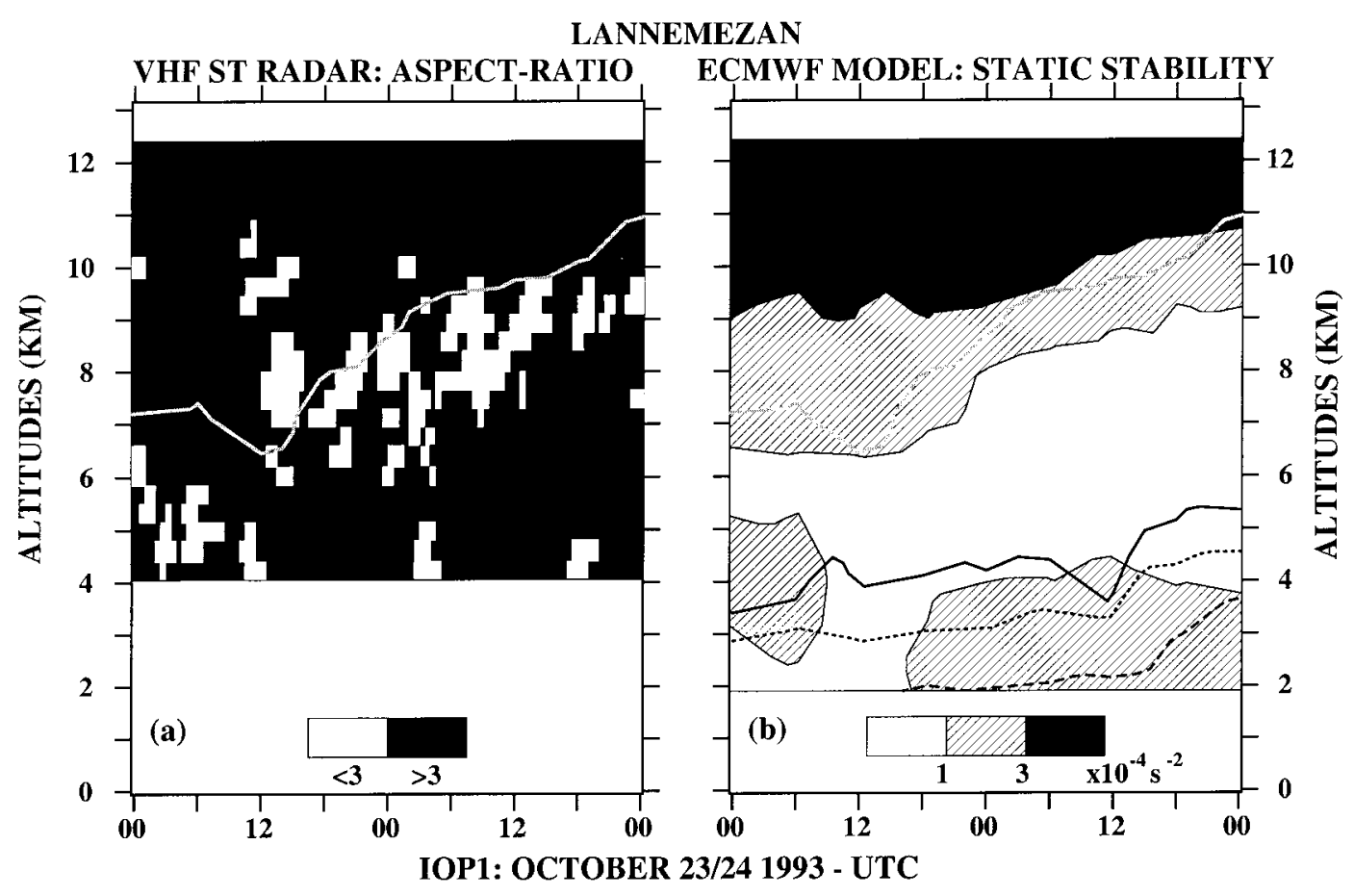

Fig. 3. Same as Fig. 2 for the Lannemezan radar during IOP1.

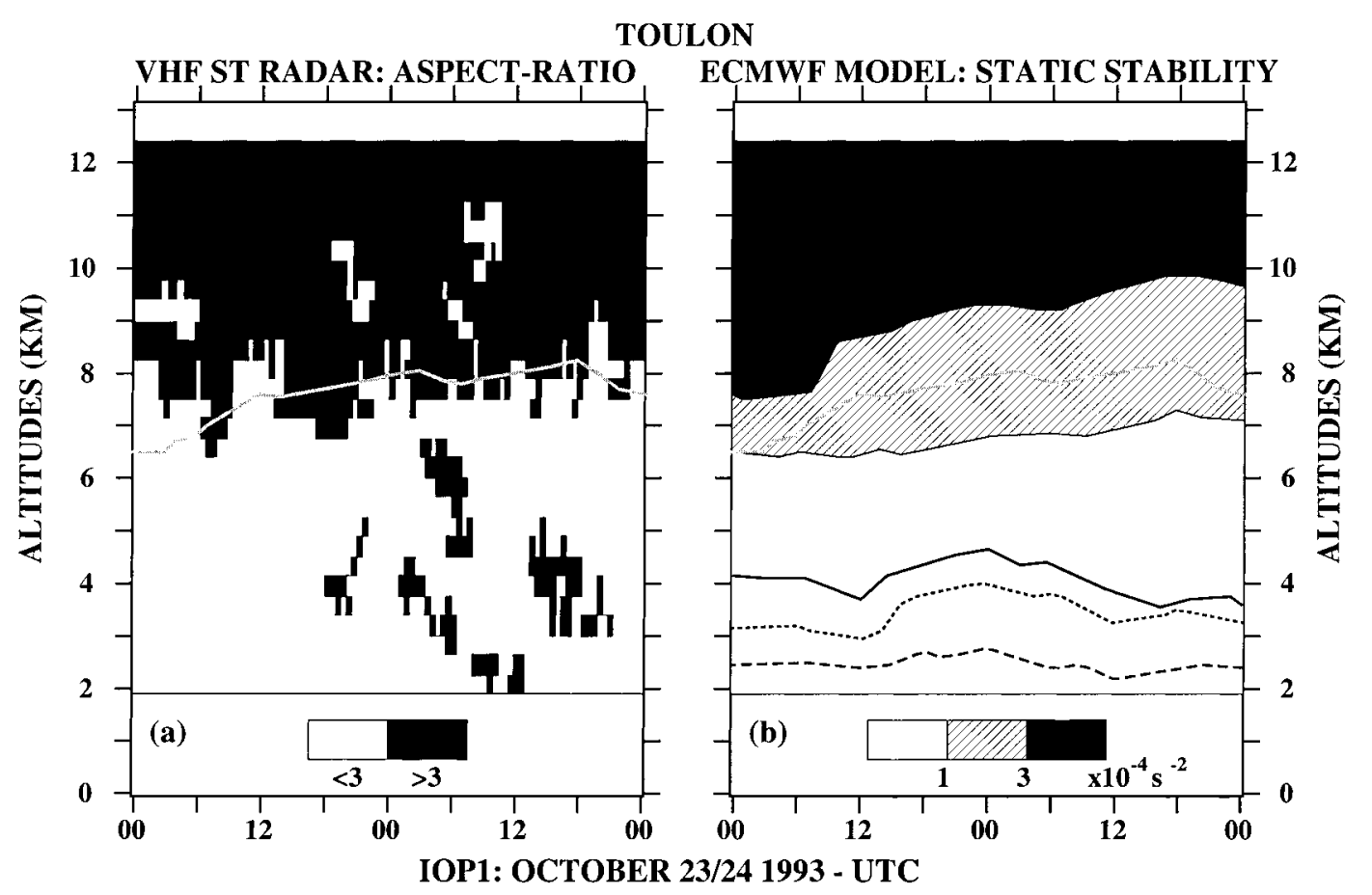

Fig. 4. Same as Fig. 2 for the Toulon radar during IOP1. 


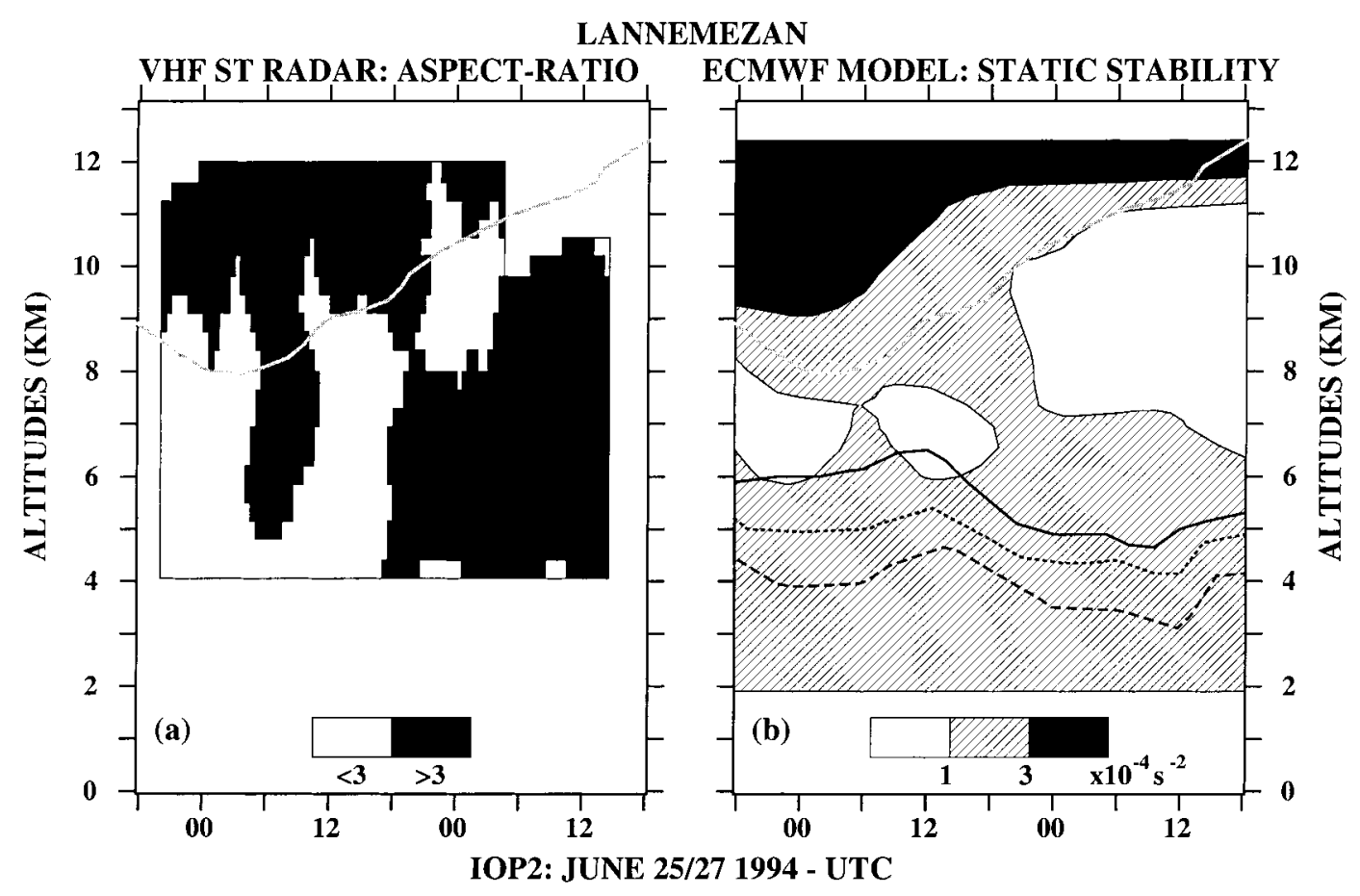

Fig. 5. Same as Fig. 2 for the Lannemezan radar during IOP2.

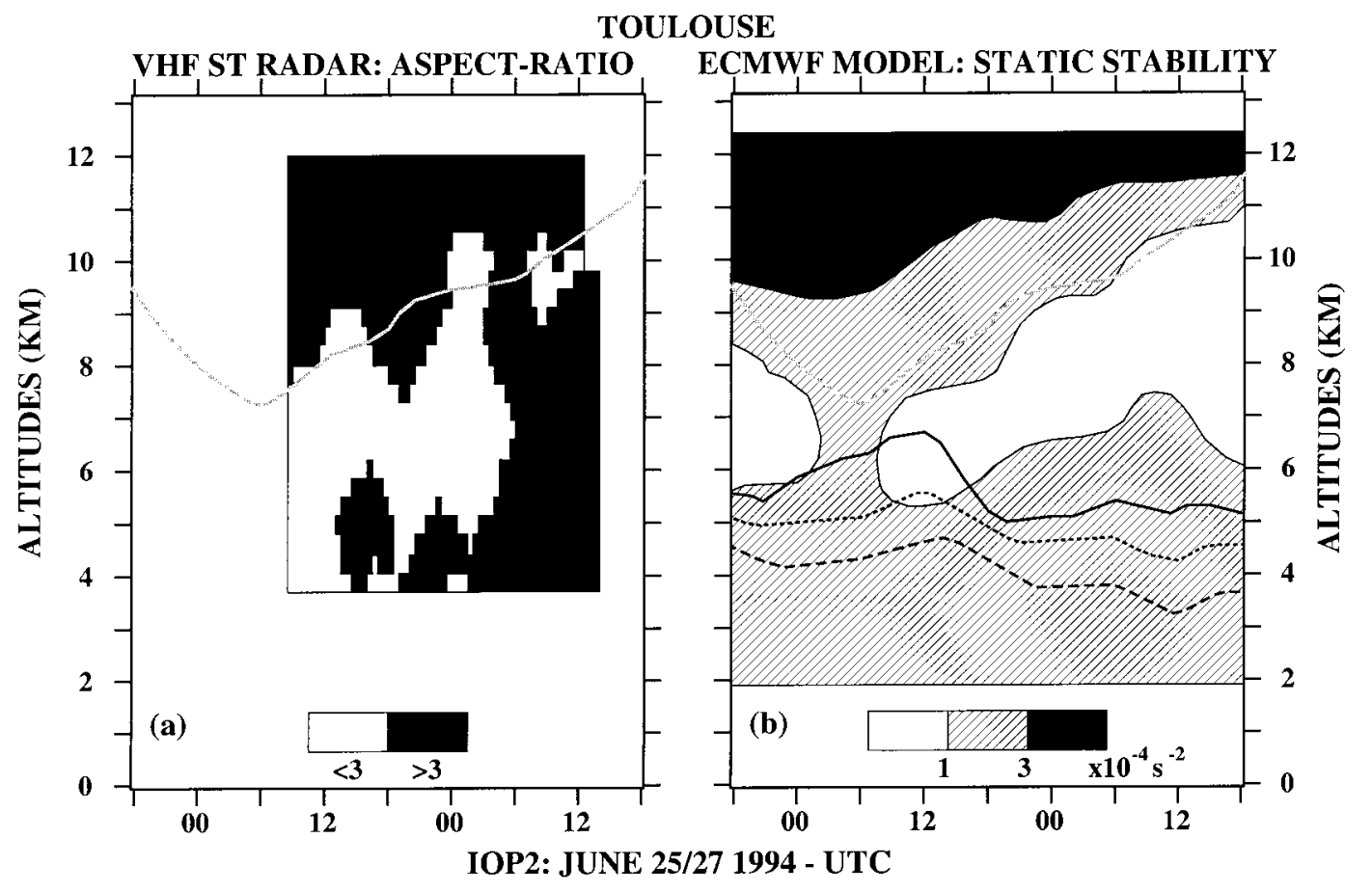

Fig. 6. Same as Fig. 2 for the Toulouse radar during IOP2. 


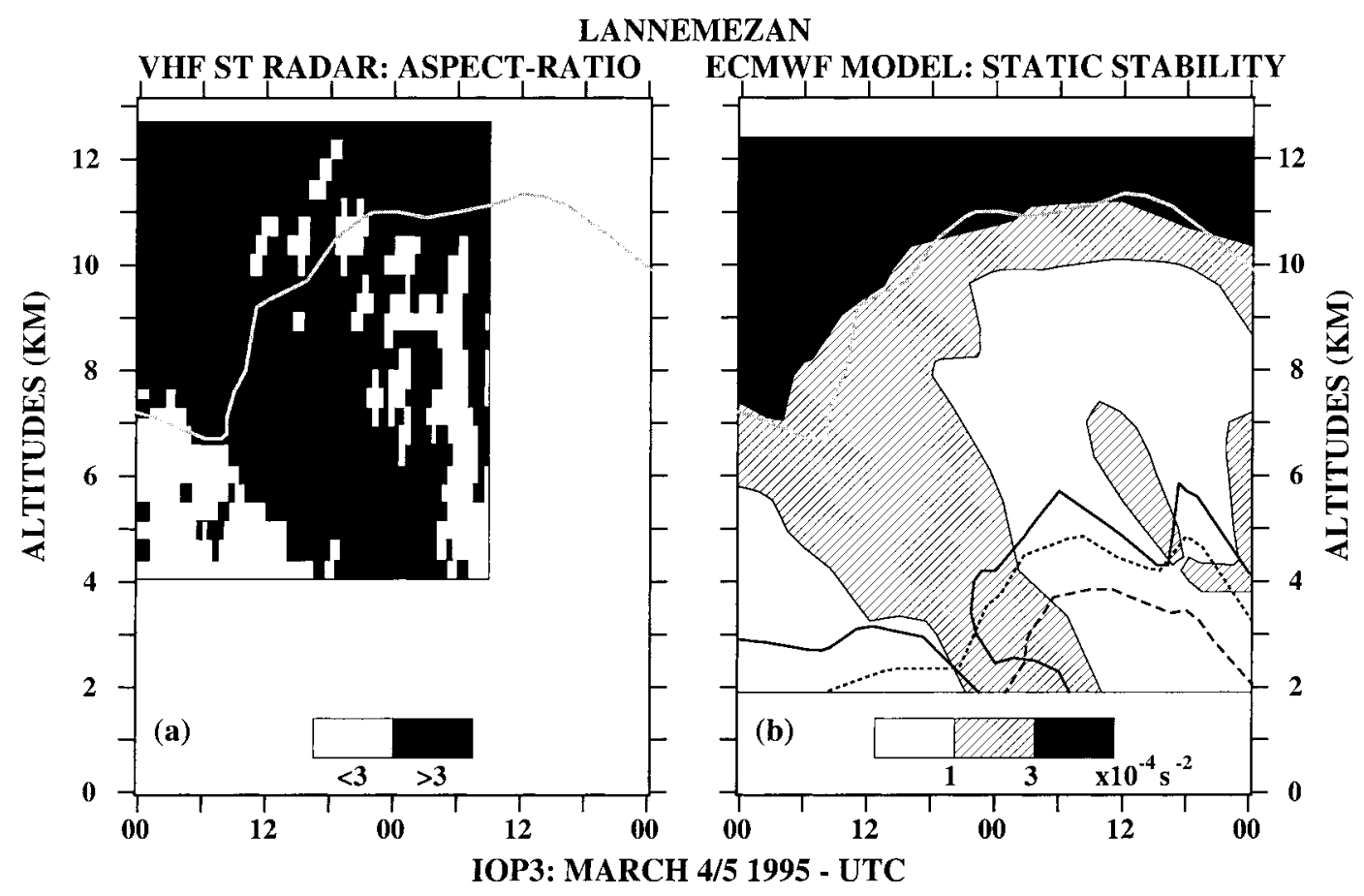

Fig. 7. Same as Fig. 2 for the Lannemezan radar during IOP3.

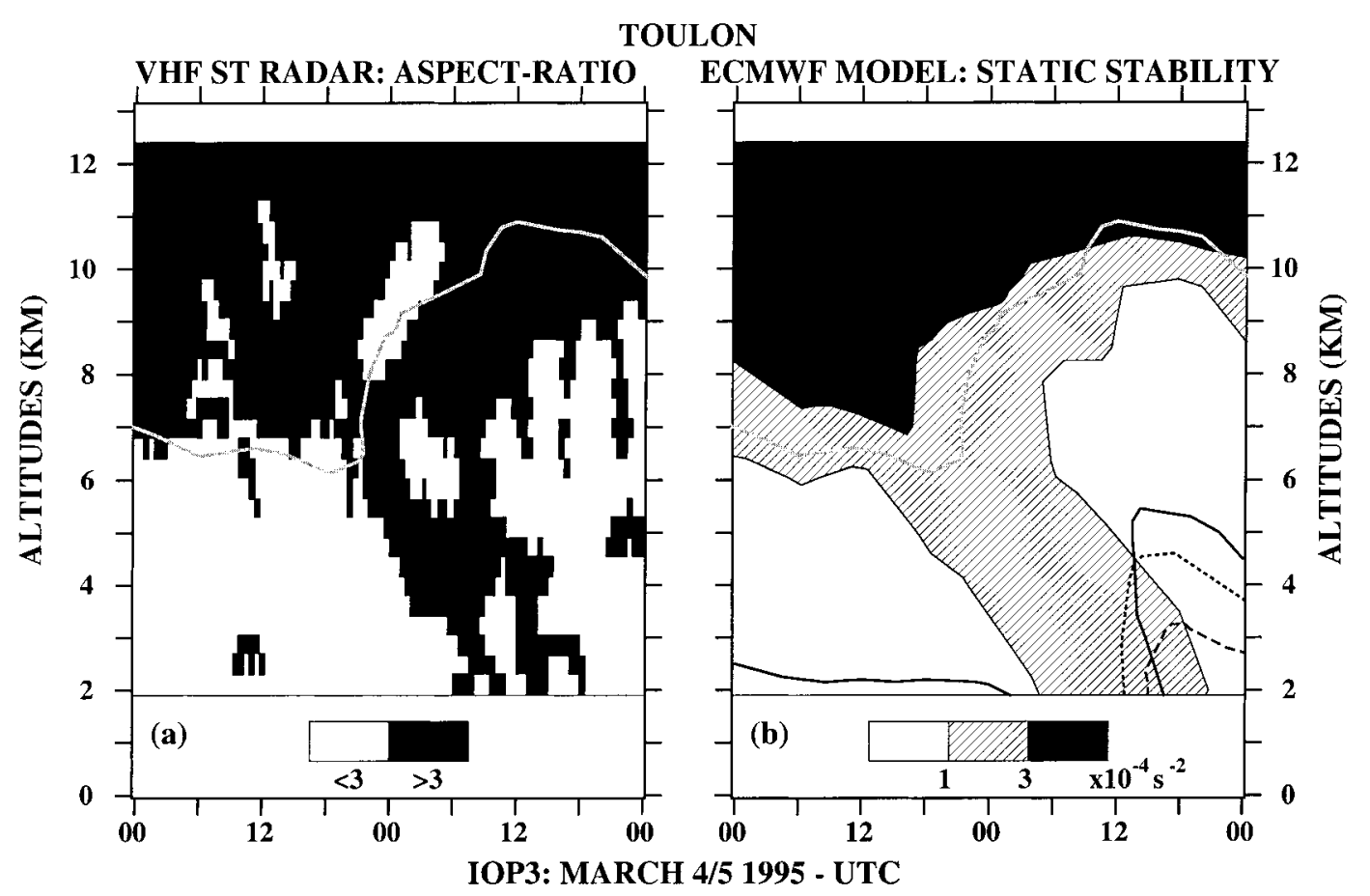

Fig. 8. Same as Fig. 2 for the Toulon radar during IOP3. 
than $0.5 \mathrm{~g} / \mathrm{kg} / \mathrm{km}$ below and above the contour line, respectively.

Fig. 2 shows results obtained by the radar of Toulon during the two days before the IOP1, when the maximum activity of the cut-off low occurred. Unfortunately, the other radars started to work at the beginning of IOP1 and missed the first part of the event because of a bad forecasting of the cut-off low beginning. Except for this particular case, the other figures show the results obtained during IOPs Figs. 3 and 4, for IOP1 (see Fig. 1(a)), Figs. 5 and 6, for IOP2 (see Fig. 1(b)), and Figs. 7 and 8, for IOP3 (see Fig. 1(c)).

\subsection{Data comparisons: method and results}

In order to make the discussion clearer, an objective method of comparison between the patterns of AR data (Figs. 2(a)-8(a)) and those of model-derived moist static stability (Figs. 2(b)-8(b)) was applied. We assumed that favourable comparisons are obtained (i) at stratospheric levels (see the areas above the gray curves), in $\mathrm{AR}>3$ time-height regions, defined by the black areas of Figs. 2(a)-8(a), and (ii) at tropospheric levels, in AR $>3$ time-height regions (black areas of Figs. 2(a)-8(a)) which coincide with model enhanced stability areas, defined by the hatched and black areas of Figs. 2(b)-8(b), and in AR $<3$ time-height regions (white areas of Figs. 2(a)-8(a)), which coincide with model weak stability areas (white areas of Figs. 2(b)8(b)). The (i) and (ii) define favourable stratospheric and tropospheric regions, respectively. Then, for each figure, the favourable stratospheric region-to-stratosphere total area-ratio (called stratospheric ratio in the following) and the favourable tropospheric region-totroposphere total area-ratio (called tropospheric ratio in the following) were computed. The higher the ratio, the better the consistency between radar data and model analyses, given that the perfect agreement corresponds to a ratio of $100 \%$. Table 2 shows the results

Table 2

Stratospheric and tropospheric ratii obtained from the comparison method ${ }^{\mathrm{a}}$

\begin{tabular}{lll}
\hline Figure number & $\begin{array}{l}\text { Stratospheric ratio } \\
(\%)\end{array}$ & $\begin{array}{l}\text { Tropospheric ratio } \\
(\%)\end{array}$ \\
\hline Fig. 2 & 73.6 & 84.5 \\
Fig. 3 & 94.5 & 30.4 \\
Fig. 4 & 87.7 & 82.6 \\
Fig. 5 & 80.7 & 53.0 \\
Fig. 6 & 89.3 & 60.8 \\
Fig. 7 & 94.0 & 69.1 \\
Fig. 8 & 87.6 & 77.4
\end{tabular}

\footnotetext{
${ }^{a}$ See the text for more explanations.
}

of the comparison method. They will be used in the discussion about the reliability of the AR method.

\section{Discussion}

Throughout the discussion, it must be kept in mind the fundamental difference between direct observations and synoptic model analyses obtained with spatial and temporal interpolations. For example, it is expected that some small-scale features, observed by the radars, are not present in the model analyses. In addition, some vertical and/or temporal differences between observations and analyses cannot be excluded. Therefore, in each figure, an overall consistency between the two panels must be sought rather than a tight agreement. The values reported in Table 2 quantify this overall consistency in both the stratosphere and the troposphere, and for all the cases presented here. A high value reveals that the corresponding case is consistent. Such a consistency, when obtained, would give confidence in the AR method, which could be used to monitor the fine structures of stratospheric-tropospheric exchanges, which is not possible with synoptic model analyses.

Following this idea and from the stratospheric ratio values reported in Table 2, a good consistency is obtained at stratospheric levels, including the tropopause level monitoring or the detection of a tropopause folding (see Figs. 7 and 8). As already mentioned in $\mathrm{CC} 98$, two reasons can explain the white patterns not expected, but sometimes visible above the tropopause. First, they can be due to a very poor SNR in the oblique-beam Doppler-spectra at such high levels. With the radar type used here, this problem exists around and above $10 \mathrm{~km}$ where SNRs lower than $-12 /-15 \mathrm{~dB}$ are obtained. Despite this problem, it is noticeable that the AR values corresponding to those white areas are generally between 2 and 3, thus not very far from the AR = 3-threshold, which supports the fact that they can be attibuted to AR estimation errors. Second, the stability can be underestimated, using the $\mathrm{AR}>3$-criterion, in stable time-height regions, where a significant turbulent layer is also present. For instance, the white coherent structure visible in Fig. 8 around 00UTC and between 8 and $11 \mathrm{~km}$, corresponds to this kind of situation (a turbulent layer exists as can be seen on the oblique echo power data not shown here). The central part of this particular area constitutes the only case where AR values between 1 and 2 are obtained at stratospheric levels. In summary, although some episodic discrepancies can be obtained, the AR method allows stratospheric air masses to be rather well detected.

On the other hand, the tropospheric ratio values of Table 2 reveal that the AR method can lead to more 
problems at tropospheric levels. Although a good or rather good consistency is obtained in Figs. 2, 4, 7 and 8 , for which tropospheric ratios are greater than $69 \%$, Figs. 3, 5 and 6, clearly show disagreements between radar data and model analyses, since the corresponding tropospheric ratios are lower than $61 \%$. In the following, these two kinds of situation are called consistent and inconsistent cases, respectively. These disagreements are now discussed in terms of humidity.

All the consistent cases, in which the tropospheric air masses of enhanced stability are rather well detected, correspond to situations where the humidity, though not entirely negligible, does not significantly reinforce the moist static stability. Indeed, no hatched patterns are permanently present at low tropospheric levels in Figs. 2(b), 4(b), 7(b) and 8(b). On the other hand, such permanent structures of moist static stability reinforced by the specific humidity are visible in Figs. 3(b), 5(b) and 6(b). This observation allows us to suspect such a combination of high specific humidity and high moist static stability to be responsible for the disagreements obtained here. In Fig. 3, the AR > 3-criterion leads to an overestimation of the stability at mid- and low- tropospheric levels, whereas, in Figs. 5 and 6 , it leads to an underestimation at the same levels, in the first part of the IOP2, and to an overestimation, mainly at mid-tropospheric levels and above, in the second part. The similarity of the radar results shown by Figs. 5 and 6 confirms that the bad detection made by the method should be related to the atmospheric situation since both the concerned radars were located only $70 \mathrm{~km}$ apart. In addition, the same similarity is obtained with the same radars, but for IOP1 (see Fig. 3, the results obtained at Toulouse being not shown here). In the following an attempt is made to explain the disagreements.

As already mentioned, the VHF echo power returned from refractive index gradient structures, thus mainly from the vertical, is proportional to $M^{2}, M$ being itself proportional to the sum of terms directly related to the static stability, the specific humidity and the specific humidity gradient. Therefore, AR can be interpreted in terms of static stability signature only if the profiles of the specific humidity and its gradient can be neglected, that is, in dry or weakly humid situations. Recently, Tsuda and Miyamoto (1998) showed that not only the humid term but also the gradient term could be of the same order, and sometimes more than, the static stability term. They also pointed out that the gradient term can lead to a magnification or a lowering of the echo power, depending upon its sign. Also, Worthington and Vaughan (1998) observed that, in strongly humid situations, the VHF vertical echo power could decrease, while the humidity increases. This result, in partial agreement with Tsuda and Miyamoto (1998), was not discussed in terms of humidity gradient. In all the cases, there is evidence that strongly humid situations associated with significant humidity gradients should lead to problems for the interpretation of AR as a static stability tracer.

The presence of significant humidity can be revealed by the humidity contours (absolute and gradient values) obtained from the ECMWF-model analyses and depicted in Figs. 2(b)-8(b). However, the effects of those contributions on the VHF echo power cannot be more deeply investigated here, since nearby high-vertical resolution profiles which would be required, mainly for realistic gradient calculations, were not available. By using the model analyses, which give smoothed and spacially interpolated information, and from our observations we can reasonably suspect the specific humidity and its gradients to be responsible for the inconsistent cases. The good consistency obtained at stratospheric levels, where the humidity is zero or negligible, supports this conclusion.

\section{Concluding remarks}

The successful use of VHF radar AR values, that is, the values of the vertical to oblique echo power ratio, greater than 3 for monitoring an upper-level front passage has already been reported (CC98) for a one-day period in a case of upper-level front passage and under weakly humid conditions. The same method was applied here to cases of cut-off low and tropopause folding passages during the ESTIME campaign. Three different situations, corresponding to a total of $506 \mathrm{~h}$ of observation time, were observed by the French network of five VHF-ST-radars and $297 \mathrm{~h}$ of observation are presented and discussed here.

The results are found to be consistent with ECMWF-model analyses at stratospheric levels. A good consistency is also obtained at tropospheric levels in dry or weakly humid situations, or when the humidity, though not negligible, has only a weak effect on the moist static stability. AR-values quasi-systematically found to be greater than 3 in the low-stratosphere supports this observation since, at these levels, the static stability is generally strong and the humidity is zero or negligible. On the other hand, our results suggest that in situations where the humidity has a significant effect on the moist static stability a unambiguous interpretation of $\mathrm{AR}$ values as a stability tracer is no longer valid.

A strong conclusion concerning this problem cannot be drawn here, since it would require more extensive investigations about the effects of the humidity and its gradients on the VHF echo power, thus on AR. The use of nearby high-vertical resolution profiles could have made possible such investigations, but such data were not available here. Analyzing results from future 
specific campaigns using simultaneous and collocated radar measurements and radiosonde ascents, and possibly mesoscale-model simulations, should help to clarify the problem.

\section{Acknowledgements}

The CNRS and the INSU are gratefully acknowledged for the financial support to this project. The authors are thankful for the effort of the staffs of the OHP, Toulouse, Clermont-Ferrand, Toulon and Lannemezan stations. The ECMWF is acknowledged for providing the meteorological analysis data.

\section{References}

Ancellet, G., Beekmann, M., Papayannis, A., 1994. Impact of a cut-off low development on downward transport of ozone in the troposphere. Journal of Geophysical Research 99, 3451-3468.

Bertin, F., Crémieu, A., Ney, R., Ancellet, G., Wilson, R., Pointin, Y., Crochet, M., Caccia, J.-L., Van Baelen, J., Klaus, V., Petitpa, A., Campistron, B., Pagès, J.-P., Van Velthoven, P., 1996. Stratospheric-tropospheric exchange studies using a network of ST radars and ozone soundings. In: Edwards, B. (Ed.), Proceedings of the 7th Workshop on MST Radar, Solar-Terrestrial Energy Program, pp. $137-140$

Caccia, J.-L., Cammas, J.-P., 1998. VHF-ST-radar observations of an upper-level front using vertical and obliquebeam $\mathrm{CN}_{2}$-measurements. Monthly Weather Review 126, 483-501.

Campistron, B., Pointin, Y., Lohou, F., Pagès, J.-P., 1999. Aspect sensitivity of VHF radar echoes observed in the middle and upper troposphere during the passage of a cutoff low. Radio Science 34, 667-680.

Crochet, M., Cuq, F., Ralph, F.M., Venkateswaran, S.V., 1990. Clear air radar observations of the great October storm of 1987. Dynamics of the Atmosphere and Oceans $14,443-461$.

Danielsen, E.F., Hipskind, R.S., Gaines, S.E., Sachse, G.W., Gregory, G.L., Hill, G.F., 1987. Three-dimensional analysis of potential vorticity associated with tropopause folds and observed variations of ozone and carbon monoxide. Journal of Geophysical Research 92, 2103-2111.

Ebel, A., Hass, H., Jakobs, H., Laube, M., Memmesheimer, M., Oberreuter, A., 1991. Simulation of ozone intrusion caused by a tropopause fold and cut-off low. Atmospheric Environment 25A, 2131-2144.

Fukao, S., Yamanaka, M.D., Matsumoto, H., Sato, T., Tsuda, T., Kato, S., 1989. Wind fluctuations near a cold vortex-tropopause funnel system observed by the MU radar. Pure and Applied Geophysics 130, 463-479.

Gage, K.S., Balsley, B.B., 1978. Doppler radar probing of the clear atmosphere. Bulletin of the American Meteorological Society 59, 1074-1093.

Gage, K.S., Balsley, B.B., 1980. On the scattering and reflec- tion mechanisms contributing to clear air radar echoes from the troposphere, stratosphere, and mesosphere. Radio Science 15, 243-257.

Gage, K.S., Balsley, B.B., Green, J.L., 1981. Fresnel scattering model for the specular echoes observed by VHF radar. Radio Science 16, 1447-1453.

Hocking, W.K., Fukao, S., Tsuda, T., Yamamoto, M., Sato, T., Kato, S., 1990. Aspect sensitivity of stratospheric VHF radio wave scatterers, particularly above $15 \mathrm{~km}$ altitude. Radio Science 25, 613-627.

Hoskins, B.J., Bretherton, F.P., 1972. Atmospheric frontogenesis models: mathematical formulation and solutions. Journal of the Atmospheric Sciences 29, 11-37.

Hoskins, B.J., McIntyre, M.E., Robertson, A.W., 1985. On the use and significance of isentropic potential vorticity maps. Quarterly Journal of the Royal Meteorological Society 111, 877-946.

Lamarque, J.F., Hess, P.G., 1994. Cross-tropopause mass exchange and potential vorticity budget in a simulated tropopause folding. Journal of the Atmospheric Sciences 51, 2246-2269.

Larsen, M.F., Röttger, J., 1982. VHF and UHF Doppler radars as tools for synoptic research. Bulletin of the American Meteorological Society 63, 996-1008.

Larsen, M.F., Röttger, J., 1985. Observations of frontal zone and tropopause structure with a VHF Doppler radar and radiosondes. Radio Science 20, 1223-1232.

Luce, H., Dalaudier, F., Crochet, M., Sidi, C., 1996. Direct comparison between in situ and VHF oblique radar measurements of refractive index spectra: a new successful attempt. Radio Science 31, 1487-1500.

May, P.T., Yamamoto, M., Fukao, S., Sato, T., Kato, S., Tsuda, T., 1991. Wind and reflectivity fields around fronts observed with a VHF radar. Radio Science 26, 1245-1249.

Neiman, P.J., Shapiro, M.A., 1989. Retrieving horizontal temperature gradients and advections from single-station wind profiler observations. Weather Forecasting 4, 222233.

Neiman, P.J., May, P.T., Shapiro, M.A., 1992. Radio acoustic sounding system (RASS) and wind profiler observations of lower- and mid-tropospheric weather system. Monthly Weather Review 120, 2298-2313.

Ottersten, H., 1969. Mean vertical gradient of potential refractive index in turbulent mixing and radar detection of CAT. Radio Science 4, 1247-1249.

Price, J.D., Vaughan, G., 1993. The potential for stratosphere-troposphere exchange in cut-off low systems. Quarterly Journal of the Royal Meteorological Society 119, 343-365.

Ravetta, F., Ancellet, G., Kowol-Santen, J., Wilson, R., Nedeljkovic, D., 1999. Ozone, temperature and wind field measurements in a tropopause fold: comparison with a mesoscale model simulation. Monthly Weather Review 127, 2641-2653.

Röttger, J., 1979. VHF radar observations of a frontal passage. Journal of Applied Meteorology 18, 85-91.

Röttger, J., 1980. Reflection and scattering of VHF radar signals from atmospheric refractivity structure. Radio Science $15,259-276$.

Shapiro, M.A., 1980. Turbulent mixing within tropopause folds as a mechanism for the exchange of chemical con- 
stituents between the stratosphere and troposphere. Journal of the Atmospheric Sciences 37, 994-1004.

Tsuda, T., Miyamoto, M., 1998. Estimation of a humidity profile using clear air echo characteristics. In: Proceedings of the 4th International Symposium on Tropospheric Profiling: Needs and Technologies, Snowmass, Colorado, Sept. 21-25, 2, 311-313.

Tsuda, T., Van Zandt, T.E., Saito, H., 1997. Zenith-angle dependence of VHF specular reflection echoes in the lower atmosphere. Journal of Atmospheric and Solar-Terrestrial Physics 59, 761-775.

Van Baelen, J., Bertin, F., Pointin, Y., Caccia, J.-L., Ancellet, G., 1994. Stratospheric/tropospheric exchange studies using a network of ST radars and ozone soundings. In: Proceedings of the 3rd International Symposium on Tropospheric Profiling: Needs and Technologies, Hamburg, Germany, Aug. 30-Sept. 2, vol. 1, 41-44.

Wirth, V., 1995. Diabatic heating in an axisymmetric cut-off cyclone and related stratosphere-troposphere exchange. Quarterly Journal of the Royal Meteorological Society 121, 127-142.

Worthington, R.M., Vaughan, G., 1998. Effects of humidity, precipitation and severe convection on VHF vertical-beam echoes. In: Edwards, B. (Ed.), Proceedings of the 8th Workshop on MST radar, Solar-Terrestrial Energy Program, pp. 69-72. 